\title{
How Do You Play When You're Prey?
}

\section{A Personal Exploration into Black Creative Healing}

\author{
Natasha Thomas ${ }^{1}$ * \\ 1 Music Therapy, Indiana University Purdue University Indianapolis (IUPUI), USA \\ *natasha.mtbc@gmail.com
}

Received: 31 August 2020 Accepted: 26 January 2021 Published: 20 April 2021

Editors: Britton Williams, Marisol Norris, Leah Gipson Reviewers: Kendra Ray, Donna Owens

\begin{abstract}
Creativity is woven into the culture of Black America. Our histories and struggles as members of the minoritized African Diaspora are recorded and passed on in song and story, in movement and design. We are - and have been - the creators of an evolving culture that is simultaneously underestimated and desired by dominant culture. This othering poses real and pressing threats to our lives and livelihoods, as we are consumed and exploited to the point of erasure; and yet we keep creating. But why? What is creativity to the Black American living in such a predatory society? And how do I, as a Black creative minoritized in a Healing profession, engage with it? How do you play when you're prey? These questions form the basis for an heuristic exploration into a video blog project entitled "Black Creative Healing," where Black creatives are recorded engaging in conversation and collaboration over concepts relating to Blackness, Creativity, and the Healing process. Through arts-based analysis of past collaborations, available publicly on Youtube, I will investigate my own motivations, inspirations and roadblocks to the creative process as a Black healer. I will interrogate the directions and intentions laid bare by my creative endeavors and seek to define a central ethos by which other Black creatives may find themselves seen and encouraged, in the interest of finding balance between the "me" that is and has been - prey, and the "me" that has only ever known - and been known by play.
\end{abstract}

Keywords: Blackness, Creativity, African Diaspora, Community Care, Autoethnography, Arts Based Research

When I ask myself the question "What is Blackness," first and foremost in my mind is the word: "Creativity."

We create to survive.

We create to cope.

We create to find - and affirm - our humanity. 


\section{On Creativity}

Creativity is an integral part of Black American identity. Our histories and struggles as members of the African Diaspora have been recorded and passed on in song and story, in movement and design, generationally for millennia. The paths we have traveled, and the communities that have birthed us - and continue to birth us - are hardly limited to the African continent, let alone Western-dominant, Eurocentric, male, cis-gendered, heteronormative history (Tarik, 2018). As a result, our impact is expansive and innovative. We are - and have been - both the products and creators of evolving and global culture that is simultaneously underestimated and desired by the dominant (Western, White, etc.) majority. It could even be said that "Black innovation fuels the popular" (Elam, 2005, p. 347), regardless of whether that is our intention as a people. As an example, music was utilized as a vehicle for coded communications and acts of resistance dating back to the times of slavery (Pyatak \& Muccitelli, 2011; Towns, 2015). But even further back than that, the ritualized use of creativity in movement, music and beyond have served as a means of connecting to ancestors and unifying heritage that is connected to wholistic ${ }^{1}$ views of land and health (Linklater, 2010; Herard-Marshall \& Rivera, 2019).

With this in mind, when the dominant audience - who does not fully understand the thing they are seeing and envying - tries and fails to duplicate what it perceives of Blackness, the oft resulting hyper-racialized stereotypes masqueraded as 'authentic' become especially horrific (Elam, 2005). As Jamila Woods emotes in her 2019 song "Baldwin" (a tribute to the late and esteemed African American writer James Baldwin), "You don't know a thing about our story, tell it wrong all the time." This repackaging of Black creativity causes harm in ways that are more than just symbolic - it detaches our innovations from the communities who birth them, which can have far-reaching impacts on our literal lives.

I am reminded of Solomon Linda, the original composer of the song Mbube, which would come to be known as "The Lion Sleeps Tonight." Originally composed in 1939 and recorded in South Africa by a White-run studio that hired Black engineers to try and push a particular type of 'authentic' but 'sellable' music, Linda's family would not be compensated for the exploitation of his work until it was used in the popular Disney's Lion King movie decades later (Milan, 2000). This meager compensation of course came decades after Linda's death in poverty, and generations of trauma were lived by his family in the aftermath of their ancestor's abuse.

This kind of exploitative drain on the resources of Black communities has parallels in many aspects of life across the African Diaspora, both in and beyond the arts. The racialization of Black Americans in particular has implications in socioeconomic status such as poverty (driven by the limitation of resources while profiting off our labor), exposure to violence, and hyper-criminalization, all of which are interrelated (Burch, 2014; Elsaesser et al., 2016). To put all this another way: America loves what its Black people produce but doesn't have any particular love for Black people themselves.

So, it would seem we (Black people) must love and care for ourselves. We innovate means of supporting each other in aims of liberation from the kind of intersectional oppression described by the Combahee River Collective (1978), and promote healthy interdependence, with an emphasis on access to resources, and leadership of those most impacted by this oppression (Piepzna-Samarasinha, 2018). In this sense, creativity becomes currency, a means of uplifting and sustaining our communities for ourselves, by ourselves. Our diasporic experiences are deeply interconnected, but not owned by any one singular facet of Blackness; they might instead be regarded as being in constant traffic across and between cultural lines and divides. It is from this point that we step into our current work.

\section{Onward to Black Creative Healing}

In late 2019, after yet another in a series of tremendous - but informal - conversations with Black colleagues on the role of the arts and creativity in Black health and well- 
ness, it occurred to me that perhaps other Black creatives within and beyond my social circle were having similar conversations. I began to think to myself that perhaps these discussions of innovation and affirmation could be shared on a broader scale. The result of this seedling thought was 'Black Creative Healing,' or BCH, a YouTube videoblog featuring conversations and collaborations between myself and other Black creatives regarding Blackness, creativity and the healing process.

Collaborators have been drawn from a variety of lived experiences in and outside of the creative arts, from the fields of social work and music performance, to literature, non-profit leadership and beyond. Between the initial public release of BCH's first episode and the time of this publication, there have been five video collaborations, and the series has since been converted to an audio podcast hosted by the Black Music Therapy Network, cohosted by Adenike Webb. The current homepage of that podcast can be found at http://www.blackmtnetwork.org/black-creative-healing. This paper is an exploration into the first three $\mathrm{BCH}$ video collaborations, all of which are publicly available via https://tiny.cc/BlackCreativeHealing and were released as two-part episodes (subsequent to these, collaborations began being released as single standalone episodes).

\section{A Journey Inward}

I have chosen to reflect on these foundational episodes in an arts-based, heuristic format, meaning that while the episodes involve myself and a collaborator, the focus in this paper will be on myself as the sole subject, and the experiential learning that occurred in me throughout the process of filming, editing, sharing, and reflecting on these public collaborations. However, the notification and consent of my collaborators that I would be publishing a piece of written work reflecting on our public process was important to me on a personal level, so a note further contextualizing their involvement in this process follows this section.

In keeping with the definition of arts-based research provided by Austin and Forinash (2005), I have engaged in a rigorous process of arts-based analysis for these past $\mathrm{BCH}$ collaborations, as a means to respond to the raw data of the episodes themselves (transcripts and video recordings) and lift the analysis to a level otherwise unattainable by words alone. In particular, I have used photography, movement, poetry, songwriting, and video editing.

My research questions, which are provided in detail in the coming methodology, can essentially be distilled down to a query posed by collaborator Zelda Lockhart in BCH Episode 3: "How do you play when you're prey?" As such, it could additionally be argued that this project also contains elements of autoethnography as well, given that there is a focus in this ultimate question that connects to a broader cultural context: one of Blackness and wholistic views of self in relation to community, pushing back against dominant individualistic narratives prominent in Western society (Creswell, 2013; Linklater, 2010).

\section{A Note on Consent}

In consulting with the institutional review board (IRB) of my current institution, the nature of research involving self-reflection on previously published work does not require the informed consent form typically required for human study research. This is for two reasons: first, because the subject is me and my writing of a paper on myself implies my consent to be studied, and second, the collaborative work being reflected on is already public. However, it was of personal importance to me that my collaborators involved in these previously published studies be reached out to prior to the beginning of this project, to inform them it was being undertaken. Reflections relating to this project have been shared with them throughout the writing of this paper, with invitations for their feedback leading up to the publication of this work. I am deeply grateful to my collaborators for their feedback and support of this project. 


\section{Positionality Statement}

I am an Afro-Caribbean (Black) American. I am a child of Caribbean immigrants and identify as queer (pronouns she/themme). I am chronically ill. I hold a PhD and work in Academia, and as such live with privileges afforded by that status, including access to financial and other economic resources. By nature of being in a hetero-apparent relationship I have the additional privilege of being able to 'pass' as straight and being called 'woman' works for me at the moment, though it does not feel to me as though 'woman' represents the full depth of my racialized gender identity. Similarly, the nature of my health conditions means that I can also pass as 'able-bodied,' with few limitations. My Blackness, however, and the racialization of that Blackness by dominant American culture is unavoidable. It informs everything that I do.

\section{Method}

Heuristic research involves self-inquiry of experiential phenomena (Moustakas, 1990). As conceptualized by Moustakas, who was a prominent originator of the American Humanist Psychology movement, the insights yielded from systematic personal exploration have the potential to serve as foundational building blocks for future phenomenological research (Mihalache, 2019). The key term here is systematic. Moustakas outlined six steps for ensuring the rigor of heuristic inquiry, including 1) initiatial engagement with the primary research question, 2) immersion with the intensity of the research topic, followed by 3 ) incubation and time away from said topic, then 4) spontaneous and natural illumination from the incubation process, 5) explicitation (explanation) of the resulting illuminations, and 6) creative synthesis, most often in the form of storytelling, as a means of relating findings (Moustakas, 1990). These steps, particularly the processes involving explanation and creative synthesis, lend themselves well to arts-based research, which frequently uses response art as a means of conveying or elevating data (Gerge et al., 2017). In fact, Gerge and colleagues lay out six steps of their own for encouraging vigor in arts-based research, which they call "Rx6":

1. Relating to the subject at hand (which could be paralleled to Moustakas' first step of initial engagement),

2. Resonating with (or immersing in, allowing incubation with, and natural illumination to arise from) the chosen subject,

3. Responding to the arising resonations (which might be viewed as a parallel to Moustakas' (1990) steps of explanation as well as creative synthesis),

4. Reflecting, in a cyclical return to the research question and process,

5. Results acknowledgment, and

6. Reacting with the newly acquired knowledge.

As I set out on my journey of self-inquiry towards investigating my own motivations, inspirations, roadblocks and desires in relation to the creative process as a Black healer, engaging in this arts-based methodology seemed the most natural way to interrogate my intentions and directional choices within a cultural context, as autoethnography seeks to do (Creswell, 2013). Essentially, I was (and am) seeking to define for myself a central ethos by which I could ultimately parse out an answer to the prompt initially posed by Zelda Lockhart, $\mathrm{BCH}$ Episode 3 collaborator, who asked, "How do you play when you're prey?" My specific research questions were as follows:

1. Why do I, as a Black American, create? What are my personal motivations, inspirations and intentions?

2. What are the personal and systemic roadblocks to my creativity and how do I work through them?

3. How do I, as a Black creative and helping professional, living in a predatory society, engage with creativity in an intentional way as a member of the broader Black community? 
For this project I chose to undertake the process of heuristic and autoethnographic investigation into the above questions in the following way:

1. Engagement with BCH Episodes 1-3 in the form of reviewing and manual coding of transcripts and video content for each episode. Coding consisted of physically highlighting and copying/pasting into their own document any quotes or moments in each episode where my motivations, inspirations, intentions, or roadblocks to the creative process were discussed or otherwise illuminated.

2. Immersive resonation with each episode in the form of poetic distillation (a poem made up of direct quotes).

3. Explanation of and responding to these poetic distillations in the form of further creative synthesis, which I allowed to naturally arise from the immersive process for each episode in their own distinct ways (movement and photography for Episode 1, visual diagramming for Episode 2 and songwriting for Episode 3)

4. Reflecting on these resulting creative works in the form of incubation (time away from the project) and journaling.

5. Acknowledging the results and reacting with this knowledge in the form of further creative synthesis, by combining my prior responses into a single music video containing still photography from my synthesis of Episode 1, visual imagery of my response to Episode 2, and the song written for Episode 3.

6. Relating this research experience back to existing literature and historical contexts of Black creativity and considering possible directions for future research in the process of constructing this paper.

\section{Results}

Initial engagement and coding of each BCH episode was intentionally focused on any quotes or moments in each episode where my motivations, inspirations, intentions, or roadblocks to the creative process were discussed or otherwise illuminated, in order to essentially jumpstart my creative investigation into my research questions. The following results are thus organized in relation to these themes (motivation/ethos/inspiration, roadblocks/challenges, and intentions), with a final section before the discussion where I acknowledge these results in their totality with further creative synthesis relating to the sense of feeling 'held' in this work.

\section{Motivation, Ethos and/or Inspiration}

Episode 1 of $\mathrm{BCH}$ featured a movement-based collaboration between myself and Anika McDonald, a social worker living and practicing in Florida. Originally from Jamaica, Anika and I explored being descendants of Caribbean ancestry (an "island baby") and how that positioning informed our perspectives on the 'Diaspora wars,' or disputes on what 'Blackness' was, between various African cultural groups, leading us to question our own creative processes in ways that I felt could only serve to deepen our authenticity. Our collaboration highlighted what I feel is the importance of embracing - rather than shying away from - complexity and diversity of expression as a Black Creative, and the ways in which collaboration can affirm one's sense of vulnerability and self-confidence simultaneously. In reflecting on our collaboration, I felt motivated to determine singular 'poses,' or ways to position my body that I felt exemplified the whole of each theme (in this case, motivation and inspiration) in the context of our episodes. For this first moment (Figure 1) I chose a broad stance, arms outstretched above my head, which is tilted upwards, gazing beyond my flexed and outstretched fingers. It felt - and looks - to me, to be very tree-like in nature, roots planted in my own history and connected deeply to the history of all members of the "African Tree" referred to in our collaboration, equally filled with anticipation and excitement of what might be, just beyond my reach. 


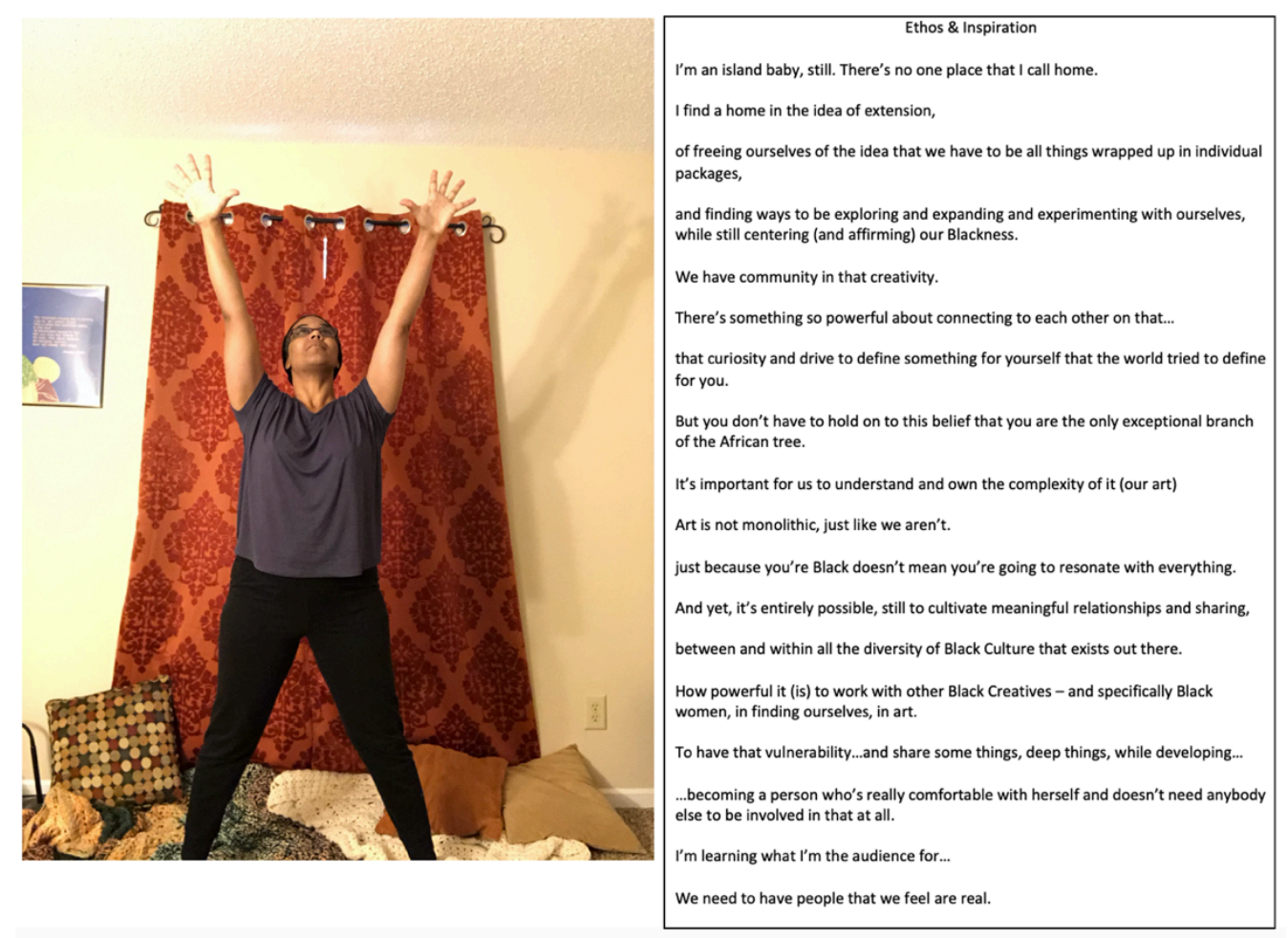

Figure 1

Ethos \& Inspiration

Tiffany Morris, or "BassMonster Tiff" and I similarly explored concepts of motivation and inspiration in our collaboration for BCH Episode 2, but each of those moments was tied strongly to the concept of intent, so we will address those moments collectively in the section dedicated to that topic.

\section{Challenges and/or Roadblocks to the Creative Process.}

Anika and I spent part of our collaboration in discussion on the various challenges to Black Creativity as well (Figure 2).

My physical positioning in the photo juxtaposed to the poetic distillation of this theme suggests a sense of apprehension about answering this question. My whole body is curled up, with much of my face hidden by my hands, almost as if my next action would be to cover my mouth. In assuming this position in the moment I recall feeling like that impending gesture of moving my hands to hide my lips was just as much about protecting me from someone trying to shove something in my mouth (like the perceptions of "Blackness" that are often 'fed' back to us in the media) as it was about a fear of opening up to speak. Additionally, the fear of speaking is not so much that I am uncertain of what to say; it's more a fear that what I say could lead to me being harmed, whether from within the African Diasporic community, as individuals and wage war internally through heavy scrutinization, or from the dominant perspective on the outside that would seek to suppress or exploit me.

Zelda Lockhart and I's discussion in BCH Episode 3 centered largely on the challenges of being a Black person in America, and how those experiences could be manifested in - and processed through - our creative endeavors. Zelda is a renowned author and has been described (by me and others) as a literary "midwife," aiding other Black Women in exploration of what she calls "personal plot" to process their own lived experiences and traumas. My poetic distillation of our collaboration, which included creative writing, vocal improvisation and even some spoken word/psychodramatic play, resulted in the following song which I present titled "There is a Girl." The lyrics to that song are as follows: 

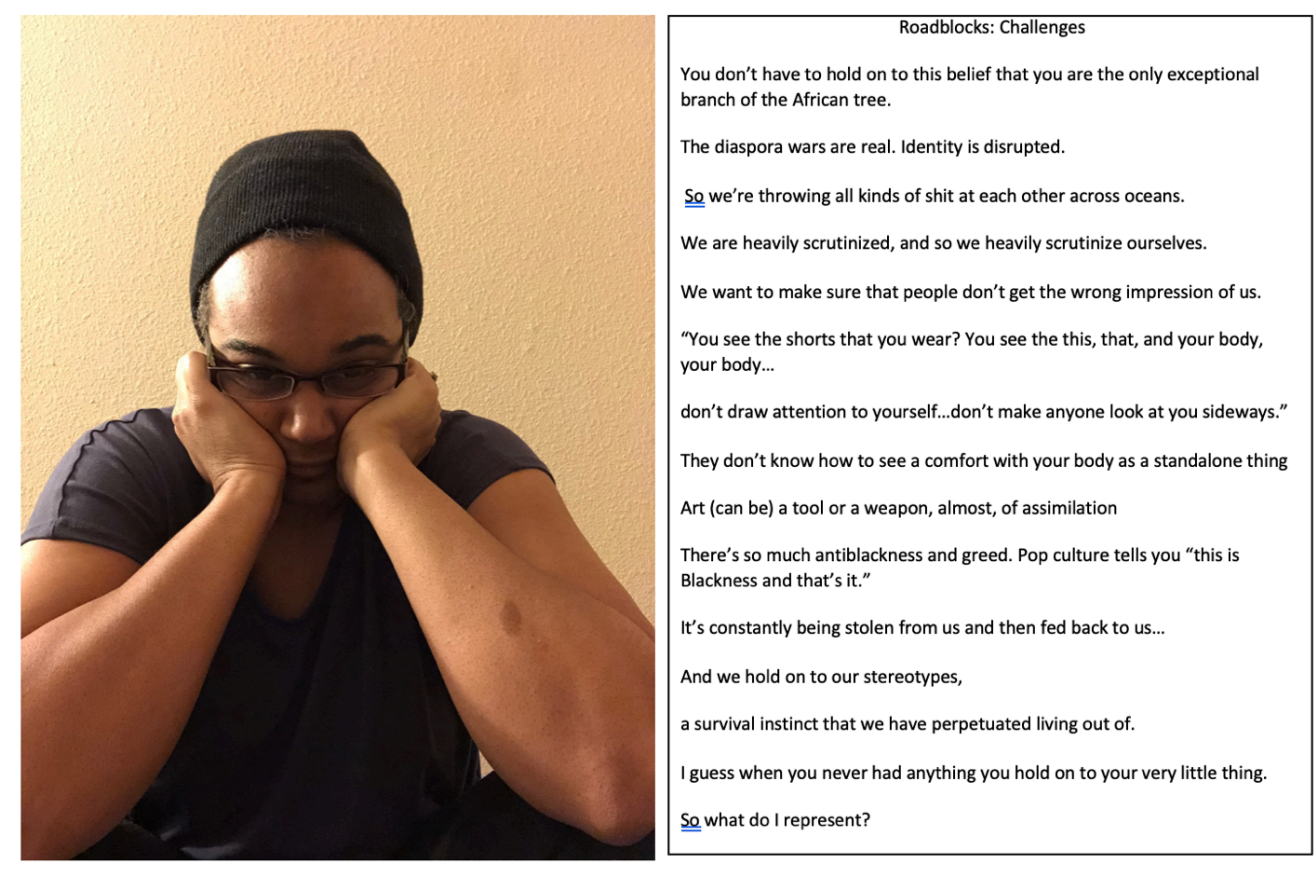

Figure 2

Roadblocks: Challenges

There is a girl I know...who finds joy in the little things.

She deserves - she deserves - to feel safe.

The fear is real. A ludicrous luxury to think beyond

the playground as anything but a gaping wound

Split open...laid bare... and nobody seems to care...

How'd it begin? Who in your lineage has told you

That every soul must be made well 'fore you can rest yourself?

Split open...laid bare...with only you to care?

Bury that weight at sea...let the tide draw you home

There is a girl I know...who finds joy in the little things.

She deserves - she deserves - to feel safe.

This time I'm in, I can't be sitting around just waiting for you

to figure it out how your sword got soaked in red.

My resilience...my grace...have nothing longer to do with you.

This space is here...for me to listen to and hold and offer story

And ritual for anyone who needs.

But my resilience...my grace...has everything to do with me.

I lay the grounds for joy... without fear of gravity...

I can't hide you. But I can stay with you tonight in community until you fall asleep.

Together...maybe...we can build a universe

In reflecting on these lyrics, I am struck by the very intentional boundaries established by Zelda and I's collaboration with regards to my ownership of the challenges I am presented with. I own the feelings those challenges elicit ("the fear is real") but interrogate their origins ("who in your lineage has told you...") and reject any implication that I have to teach any of the individuals responsible for those challenges or their resulting feelings. In fact, the only person to whom I am solely responsible is myself ("my resilience...my grace...have nothing longer to do with you...everything to do with me"). And yet, I feel a draw and responsibility - to my blood and chosen family, and my child in particular, who is not explicitly named in the song, but might as well be - and to those who engage with me as fellow travelers ("I can't hide you, but I can 


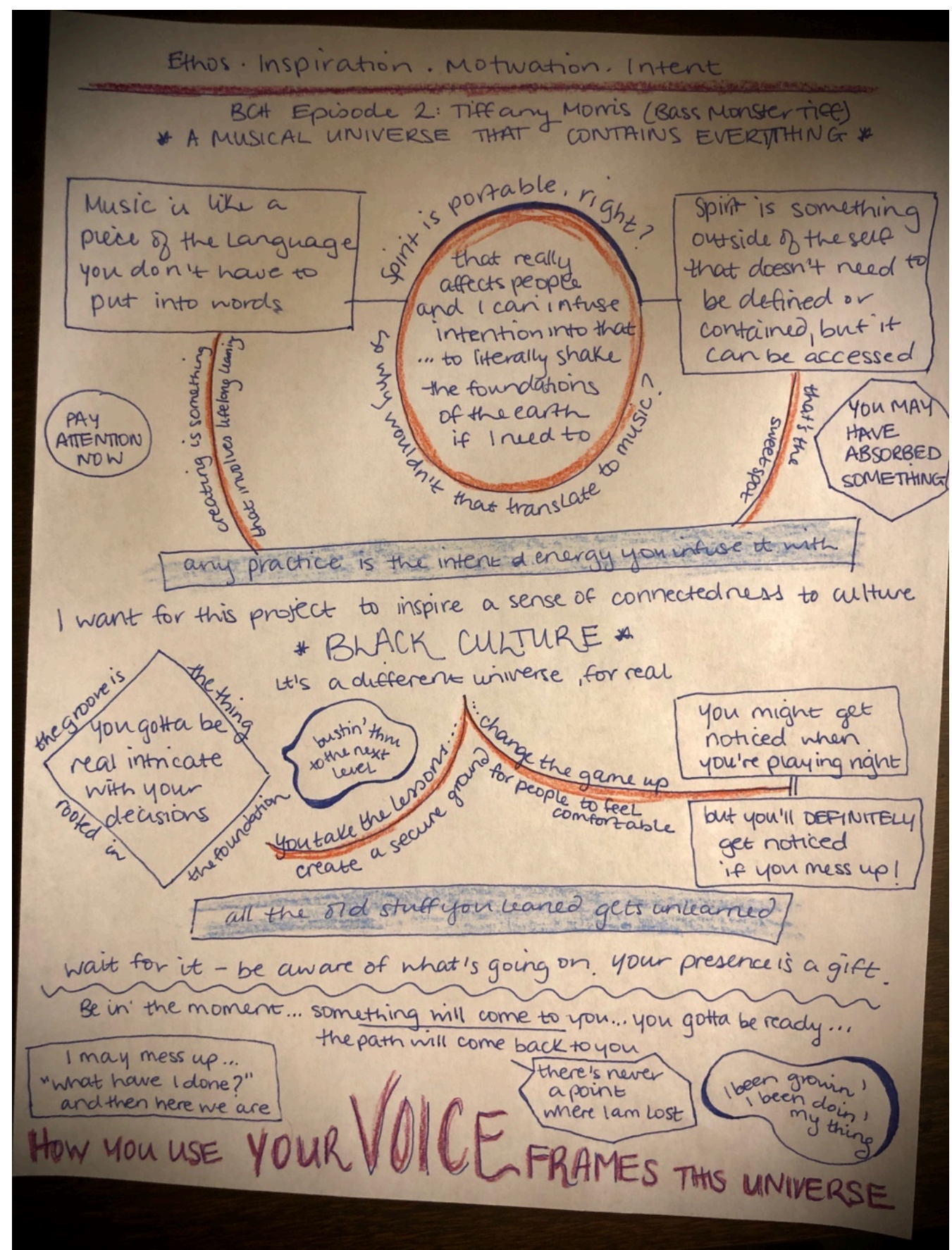

Figure 3

Ethos - Inspiration - Motivation - Intent

stay with you tonight in community..."). I am motivated to create out of a desire to see this world become a better place with fewer of the roadblocks I experienced ("together...maybe...we can build a universe"). That vision of a brighter future is what I hope I - and my work - represent.

\section{Intentions}

Themes of intentionality are woven throughout all three of the BCH collaborations on which I chose to focus for this paper, but most prominently in Episode 2 featuring Tiffany Morris (Figure 3).

Tiffany, who goes by BassMonster Tiff online, is a child of New Orleans (a term I prefer to calling someone a New Orleans Native), and bass player for several bands, most notably Cyril Neville of the Neville brothers. She and I in our collaboration dis- 


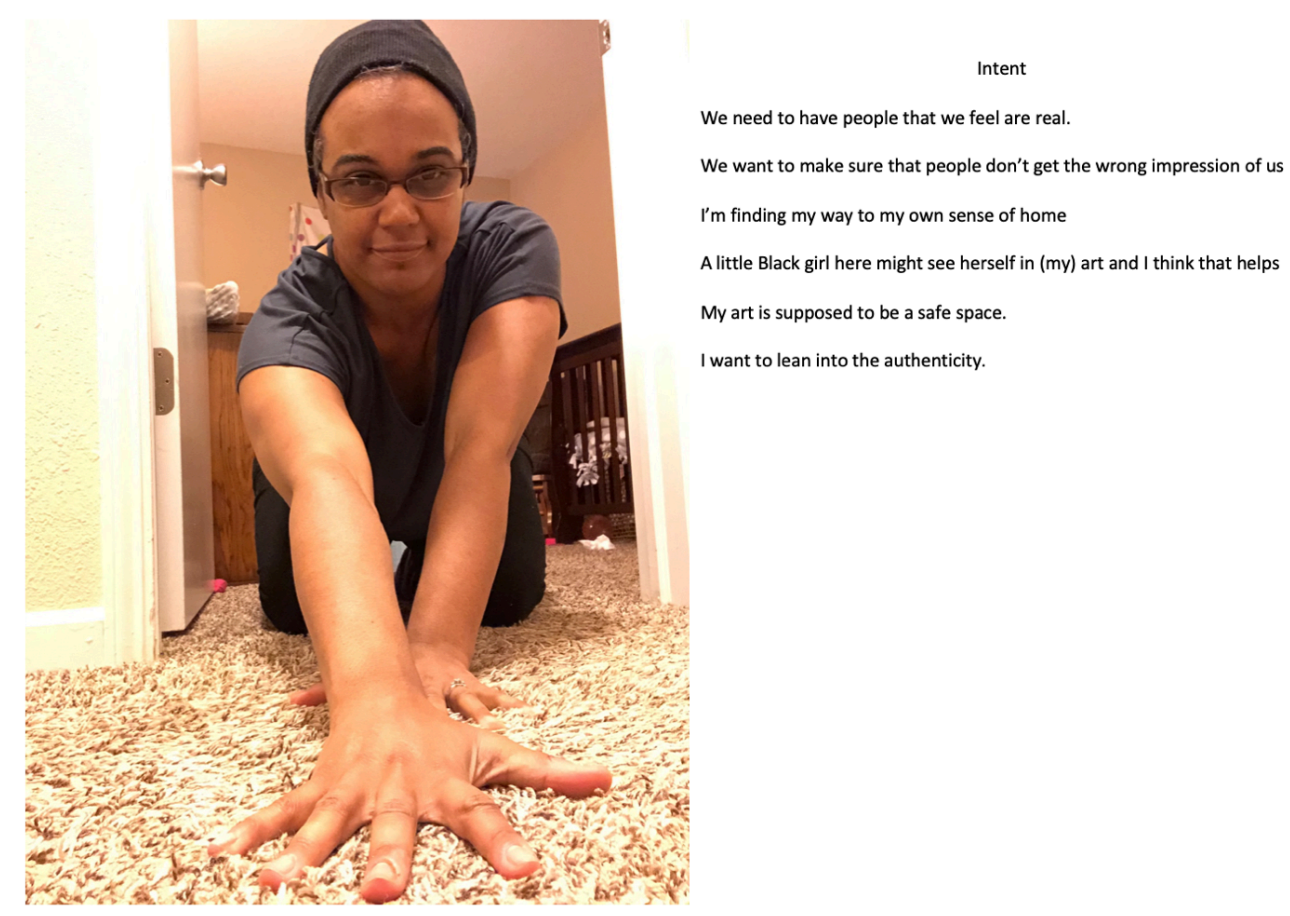

Figure 4

Intent

cussed connections between music and spirituality, and particularly the role of presence in helping to craft intentionality in musical choices and meet personal spiritual needs. The idea of music and spirit as related concepts, intangible and yet accessible and powerful, resonates strongly with me, still. I am particularly struck in reflecting on this collaboration how both Tiff and I placed a strong emphasis on the importance of lifelong learning, and studenthood as a key to honing your intentions in any realm ("you take the lessons...change the game up...something will come to you...you gotta be ready"). There are also points made that had less emphasis on them at the time, and were in fact presented in moments of levity, that hold tremendous weight for me now in reflection, particularly the idea of being gentle with oneself as a learner. "I may mess up (but) the path will come back to you..."

Organizing the poetic distillation of Tiff \& I's collaboration into a visual diagram was something that came naturally, in part as a way to break up my academic instinct for a linear process, while still being systematic in defining our focus and conversational direction. It felt important to honor the cyclical and interwoven nature of the topics Tiff and I discussed. As a result, quotes that may not have occurred in the same span of time in our recordings became tied together on the page with lines connecting them, or shapes being drawn around them, almost as signposts to direct the flow of your eye across the ideas. If you begin at the top of the page with "any practice is the intent and energy you infuse it with," your eye is drawn downward to "all the old stuff you learned gets unlearned," and closing at the bottom of the page with the largest bit of text, stating "how you use your voice frames this universe." 'Smaller' ideas like "pay attention now" or "you might have absorbed something" serve almost as guardrails weaving around and through the progression downwards, or perhaps they function more like speed bumps, encouraging you to pause and sit with peripheral thoughts around each of the 'main' ideas as you progress in this directional - but winding - way.

Anika and I discussed these elements of intent in our collaboration with a similarly winding and reflexive view, as something that is rooted in and guided by our learning, but also with gentle directness in terms of how we define ourselves for ourselves (Figure 4). 
Safety and authenticity are paramount to the kind of engagement in creativity that Anika and I have undertaken together - and I'd venture to say this was true for my other collaborators as well. Whether engaging alone or with others, "we need to have people we feel are real." Specifically, I want for the worlds created with our work to be accessible - but also protected - spaces, in which all of us (myself included) can be who we are, in community and fluidity. We need room to explore and grow as we do this. "I want my art to be a safe space. I want to lean into the authenticity." My body positioning in the photo accompanying this poetic distillation reflects this. I am low to the ground, accessible at the eye level of a child, with my arms outstretched forward, but palms facing downward towards the floor, almost as if feeling my way ahead, with an invitation to meet whoever is before me, in safety, yes, but also in authentic and meaningful play.

\section{Acknowledgment (and the Sense of Feeling 'Held')}

In considering how best to synthesize the above results together, it seemed natural to do so in a lyric video format, integrating all of the previous elements of distillation. That video can be found at https://youtu.be/w-DXD6a0Pug. The music from the song I had written in response to my collaboration with Zelda from Episode 3 provided the score, with lyrics displayed on the screen throughout the video. Lyrics are alternately presented against still photos from my syntheses of Episodes 1 and 2, or a background featuring various shades of an almost ocean-like blue-green color, animated to move in a wavelike pattern, intermixed with fresh video of me sitting and/or moving in response to the music. In the final minutes of the video I sit still in a meditative pose, with palms open on my lap, eyes closed initially, then opening to look directly into the camera. It is arguably the most vulnerable thing I've ever done, to simply sit in presence with my camera, knowing that on the other side of that lens endless miniscule moments are being captured and will be viewed by who knows how many people, including people who may say "I don't get this?" or "What is she doing?" or "This is ridiculous/terrible/I hate this person and everything about them." I realize that last perspective might seem far-fetched to some readers, but when you are a Black woman on the internet, it is sadly not uncommon - and an experience I've had more than once - to become the target of unusually personalized vitriol from white supremacists (or advocates of white supremacy) online. And yet, I am also mindful in those vulnerable final minutes of my lyric video that that moment means something to me and may mean something to someone else. In fact, I am mindful in that moment that I am undoubtedly part of a lineage of people who have embarked on similar explorations. And so - as I gaze into the camera - I am really looking for, and at, them: the people who I know will understand, and sitting in certain presence with those who already do, and have understood this process, long before I thought to undertake this journey myself. Perhaps that, too - that vulnerability and sense of resolve amidst a sea of uncertain certainty - perhaps that is Blackness too. Perhaps that is how we play when we are prey.

\section{Discussion \& Conclusion}

What began as a YouTube videoblog featuring conversations and collaborations between myself and other Black creatives has yielded some much-needed affirmations for myself, and perhaps others too, through the creative heuristic and autoethnographic process I underwent to re-visit and interrogate my role as a Black creative.

In seeking to answer the broader query of "How do you play when you're prey," I've touched on three key areas from my more detailed research questions. Those areas included: motivation (why do I create), roadblocks, and placing my creative engagement in an intentional context. Reflected in discussions by Tarik (2018) and Rivera and Herard-Marshall (2019) on the origins of Black creativity are my motivations to embrace the historical and present complexity inherent in being a Black person. I feel myself as part of a lineage of creatives that have operated long before and well beyond the 
colonization of Africa's land and peoples, with an ongoing commitment to lifelong studenthood that honors that lineage. I am forever honing the process of defining myself for myself, in hopes that my engagement and sharing of this process will help someone else to do it too. I am motivated to do this even through roadblocks similar to those threats of cooptation and exploitation described by Elam (2005) and Milan (2000), as I fear for the harm that is so often enacted on Black folks who speak or act in opposition to dominant narratives. I am constantly on guard against my creativity being weaponized against me, a scenario that sustains itself in an ongoing battle against selfsabotage amidst systemic threats.

Through all of this, I set very intentional boundaries around myself as a Black creative. I contextualize my work as an accessible protected space in which I-and any others who share that space with me-can be a whole person, in fluidity and vulnerability. Much like the care practices laid out by the Combahee River Collective (1978) and Piepzna-Samarasinha (2018), I craft my work and the spaces in which it occurs with mindfulness towards ancestral wisdom and a view of a brighter future that can be co-constructed in community.

I feel this work also yields exciting possibilities for the future of creative exploration into the various communicational codes, acts of resistance, and innovation contained in, and perpetuated by, members of the African Diaspora since before - and beyond! slavery and systemic oppression (Pyatak \& Muccitelli, 2011; Towns, 2015). Dominant culture may never fully understand what it perceives of my - or other - embodied interpretations of Blackness (Elam, 2005). But I am held by the creative practices of my ancestors before me, and there is opportunity here - by engaging in further conversations and collaborations between Black creatives - to further enrich our understanding of creativity within the Diaspora and build stronger networks for more meaningful community connections. These connections can then serve to sustain the vital flow of our life-affirming innovations to - and for - the peoples who birth them.

This has implications well beyond the arts. Deeper and more firmly established connections within Black American communities in particular could impact individual and communal socioeconomic status through the visibility and interconnectedness of resources created by and for the community. It may also serve to disrupt the exposure to violence (or providing healthy opportunities for processing that exposure), that can so often lead to our hyper-criminalization and related harm (Burch, 2014; Elsaesser et al., 2016). In this way, our love for ourselves as members of the African Diaspora becomes a tangible form of community care (Combahee River Collective, 1978; Piepzna-Samarasinha, 2018). On one level, a Black creative somewhere engaging with my work may find themselves feeling more seen and encouraged by an exploration of the Black self that is - and has been - prey yet is also known and held in ancestral love and community, by play. They may see in my vulnerability an invitation to hold their own, to look inward to their own fears and roadblocks with gentleness and find their own fire: their own lineage to tap into. Ultimately, on a deeper level, it is my hope to connect Black creatives to each other in our sense of being held - by each other, by our communities, and our ancestors, in ways that deepen our communal and ancestral bonds, and sustain the flow of creativity that affirms our path towards collective liberation. We deserve all of that, and more.

\section{About the author}

Natasha Thomas, PhD is a Board Certified Music Therapist (MT-BC) and Assistant Professor at Indiana University Purdue University at Indianapolis (IUPUI). She serves on the steering committee of the Black Music Therapists Network (BMTN) and co-facilitates the BMTN sponsored podcast "Black Creative Healing" with Adenike Webb. Natasha is also serving with Marisol Norris as co-editor of an upcoming special issue from the Journal of Music Therapy on equity \& justice. Natasha is a committed advocate for creative \& culturally sustaining support for marginalized communities. Her current research focus involves Black creativity, particularly identity construction and 
community care. Natasha's research and clinical work are inclusive of emerging technology, as well as the perspectives of disability and queer identities, and the unique ways those perspectives and resources can intersect to impact quality of life, identity construction and meaning making.

\section{Notes}

1. "Wholistic is a term derived by Renee Linklater (2010) as a means of decolonizing the term "holistic." The author seeks to remove the implied aspiration of Western "holiness," in favor of emphasizing a "wholeness" of personhood that is rooted in community.

\section{References}

Austin, D., \& Forinash, M. (2005). Arts-based research. In B. L. Wheeler (Ed.), Music therapy research (2nd ed., pp. 458-471). Barcelona Publishers.

Burch, T. (2014). The old Jim Crow: Racial residential segregation and neighborhood imprisonment. Law \& Policy, 36(3), 223-255.

The Combahee River Collective. (1978). The Combahee River Collective Statement. Zillah Eisenstein.

Creswell, J. (2013). Qualitative inquiry and research design: Choosing among five approaches. Sage Publishing.

Elam, H. J. (2005). Spike Lee’s 'Bamboozled.’. In H. J. Elam \& K. A. Jackson (Eds.), Black cultural traffic: Crossroads in global performance and popular culture (pp. 346-352). University of Michigan Press.

Elsaesser, C., Hong, J. S., \& Voisin, D. R. (2016). Violence exposure and bullying among African American adolescents: Examining the protective role of academic engagements. Children and Youth Services Review, 70, 394-402, https://doi.org/10.1016/ j.childyouth.2016.10.010.

Gerge, A., Wärja, M., \& Nygaard Pedersen, I. (2017). Using aesthetic response - A poetic inquiry to expand knowing, Part I: The Rx6-Method. Voices: A World Forum for Music Therapy, 17(1), https://doi.org/10.15845/voices.v17i1.890.

Herard-Marshal, N., \& Rivera, M. (2019). Embodied resilience: Afro-Caribbean dance as an intervention for the healing of trauma in dance/movement therapy.

https://www.criticalpedagogyartstherapies.com/single-post/2019/02/01/embodiedresilience-afro-carribbean-dance-as-an-intervention-for-the-healing-of-trauma-in.

Linklater, R. (2010). Decolonizing our spirits: Cultural knowledge and Indigenous healing. In S. Marcos (Ed.), Women and Indigenous religions (pp. 217-232). Praeger.

Mercer, K. (2005). Diasporic aesthetics and visual culture. In H. J. Elam \& K. A. Jackson (Eds.), Black cultural traffic: Crossroads in global performance and popular culture (pp. 141-161). University of Michigan Press.

Mihalache, G. (2019). Heuristic inquiry: Differentiated from descriptive phenomenology and aligned with transpersonal research methods. The Humanistic Psychologist, 47(2), 136-157, https://doi.org/10.1037/hum0000125.

Milan, R. (2000). In the jungle: Inside the long, hidden genealogy of 'The Lion Sleeps Tonight'. Rolling Stone, https://www.rollingstone.com/music/music-features/in-the-jungle-inside-thelong-hidden-genealogy-of-the-lion-sleeps-tonight-108274/.

Moustakas, C. E. (1990). Heuristic research: Design, methodology, and applications. Sage Publications.

Piepzna-Samarasinha, L. L. (2018). Care work: Dreaming disability justice. Arsenal Pulp Press.

Pyatak, E., \& Muccitelli, L. (2011). Rap music as resistive occupation: Constructions of Black identity and culture for performers and their audiences. Journal of Occupational Science, 18(1), 48-61, https://doi.org/10.1080/14427591.2011.554154. 
Tarik, L. A. (2018). Travel notes: Pan Africanism (re)visited: From Sankofa to Afrofuturism-summary of the "2nd Kwame Nkrumah Pan-African Intellectual \& Cultural Festival.". Journal of Pan African Studies, 12(1), 537.

Towns, A. R. (2015). The (racial) biases of communication: Rethinking media and blackness. Social Identities, 21(5), 474-488, http://dx.doi.org/10.1080/13504630.2015.1093469.

Woods, J. (2019). Baldwin[Song]. Legacy! Legacy!, Jagjaguwar. 